\title{
A representação do movimento no português paulista
}

RESUMO: Este trabalho tem como objetivo analisar de que maneira o movimento pode ser organizado e representado no Português Paulista em corpora dos séculos XVIII a XX. Para tanto, analiso os padrões de combinação propostos por Talmy (2000b) e a representação dos pontos do percurso num deslocamento no espaço físico. A análise é qualitativa e quantitativa, e nesse caso, levei em conta as propriedades discursivas dos textos que compõem os corpora à luz do modelo de Tradições Discursivas.

Palavras-chave: espaço, movimento, semanticização, Português Paulista, Linguística Cognitiva.

\begin{abstract}
The aim of this article is to analyze how motion can be organized and represented in Paulista Portuguese (Portuguese spoken in São Paulo), in data taken from several genres of text from the $18^{\text {th }}$ to the $20^{\text {th }}$ centuries. I take into account the patterns proposed by Talmy (2000b), and the representation of path points in motion events. The analysis is qualitative and quantitative, taking into account the discursive properties of the texts in the corpora, based on the Discourse Traditions model.
\end{abstract}

Keywords: motion event, semanticization, discoursivization, Paulista Portuguese, Cognitive Linguistics.

Introdução

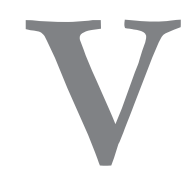

ários estudos lingüísticos envolvendo a categoria cognitiva de ESPAÇO vêm sendo realizados sobre línguas como inglês, alemão, francês, espanhol etc. (Talmy 2000a,b, Slobin 1996, Dirven \& Pütz 1996, García-Miguel 2006, entre outros). Sobre o português, destacam-se os trabalhos de Castilho (2005), Castilho et al. (2002),

Universidade de São Paulo. E-mail: kewitz@usp.br 
Batoréo (1998, 2006, 2008), Teixeira (1998), Kewitz (2007), entre outros. Ilari et al. (2008) apresentam uma análise minuciosa das preposições com base na Lingǘstica Cognitiva e em dados da variedade culta do Português Brasileiro (Projeto NURC). Grande parte desses estudos adota uma perspectiva semasiológica, ou seja, toma por base determinados itens lingüísticos para examinar sua rede de sentidos. O estudo de Pontes (1992) parte de uma análise onomasiológica do espaço e do tempo na língua portuguesa e revela que as preposições (e locuções) e os advérbios (e locuções) são as categorias espaço-temporais por excelência.

A presente pesquisa procurará ampliar os estudos sobre o Português, tomando como ponto de partida a abordagem onomasiológica, com base no uso da língua na variedade paulista. Para tanto, serão consideradas as expressões representativas de movimento em diferentes corpora dos séculos XVIII, XIX e XX. Este texto é um apanhado dos resultados obtidos na pesquisa de pós-doutoramento (Unicamp, FAPESP Proc. N. . 07/59707-5), inserida no Projeto de História do Português Paulista.

$\mathrm{Na}$ primeira parte, apresento alguns conceitos da categoria cognitiva de espaço. No item 2, trato da representação de movimento, comçando pela discussão em torno da classificação proposta por Talmy (2000b). Na última parte desse mesmo item, analiso as tendências do Português Paulista quanto aos pontos do percurso. Por fim, no item 3 discorro sobre as propriedades discursivas dos textos que compõem os corpora utilizados e a sua relação com a representação do movimento.

\section{A categoria cognitiva de espaço}

A Lingǘstica Cognitiva ${ }^{1}$, em geral, preocupa-se com questões que vão além da estrutura, sobretudo com temas referentes à capacidade mental do ser humano em descrever o mundo ao seu redor. A língua não espelha o que vemos, mas sim como vemos e como conceptualizamos o que vemos. A percepção diz respeito à interação entre aquele que percebe e o mundo percebido e depende de habilidades, experiências e estados cognitivos daquele que vê e percebe o que é visto (cf. Wenz 1996: 285). As expressões lingüísticas representativas da categoria de espaço nos dão pistas ou insights de como o mundo é percebido.

O espaço é tido como um componente cultural disponível aos falantes e que possibilita a criação de conceitos mais abstratos e a organização do 
pensamento. Porém, o processo de organização mental é muito mais complexo de ser analisado, uma vez que o que temos em mãos são os produtos ou resultados desse processamento mental: as expressões lingüísticas nos seus mais variados contextos comunicativos, dentre elas as expressões que representam o espaço. Por outras palavras, a língua e sua descrição podem ser usadas como um instrumento para construir um mundo via categorização. Ao mesmo tempo, a língua dá acesso aos princípios que são a base dessa construção cognitiva: Wenz (op.cit.).

Mudanças na nossa concepção de mundo podem acarretar transformações em sistemas conceptuais já existentes: Blank (1999: 72). Uma vez que a língua faz parte desse sistema, pode haver transformações em sua estrutura também, seja ela fonológica, morfológica, sintática, semântica, lexical ou discursiva. O número de possibilidades de codificação espacial nas mais diversas línguas mostra como é difícil explicá-las por uma única teoria, pois envolve fatores intra e extralingüísticos. Em função disso, procurei analisar as expressões espaciais levando sempre em conta a caracterização sócio-discursivas dos textos que serviram de base para a coleta de dados.

O refinamento da análise se dá a partir do conceito de língua assumido aqui: trata-se da abordagem multissistêmica proposta por Castilho $(2007,2010)$, em que se postula a língua como um sistema complexo composto por produtos e processos ${ }^{2}$. Dentre os processos aqui estudados, destacamos a semanticização e a discursivização, de que trato nos próximos itens.

\section{Sematicização do evento de movimento}

A semanticização pode ser definida como o processo de criação e mudança de sentidos. Numa perspectiva onomasiológica, examinei os dados a partir das seguintes questões: que estratégias de construção da cena espacial, mais especificamente do evento de movimento, são selecionadas?

Um evento é definido, segundo Talmy (2000b). como uma porção da realidade que foi delimitada ou recortada pela mente humana. Em suas palavras,

1 Não há uma única Linguística Cognitiva, mas sim um conjunto de teorias cognitivas da linguagem. Para mais detalhes, v. Salomão (2006).

2 Para mais detalhes dessa abordagem, v. Castilho (2007, 2010). 
(...) the human mind in perception or conception can extend a boundary around a portion of what would otherwise be a continuum, whether of space, time, or other qualitative domain, and ascribe to the excerpted contents within the boundary the property of being a single unit entity. (Talmy, 2000b: 215).

Um evento de movimento básico consiste no deslocamento de um objeto (Figura) em relação a outro (Objeto/Ponto de Referência ou Fundo $\left.{ }^{3}\right)$. Esse evento pode ser analisado a partir dos seguintes componentes: além da Figura e do Ponto de Referência (doravante, PR), estão presentes o Movimento em si, o Percurso e um Co-evento. O elemento Percurso refere-se à trajetória seguida pela Figura em relação ao PR. O Co-evento, geralmente, relaciona-se às noções de Modo ou Causa do Movimento: Talmy (2000b: 25).

Com essas definições, o autor estabelece uma classificação para as línguas: verb-framed e satellite-framed. No primeiro grupo, inserem-se as línguas românicas, turco, japonês, basco etc. Segundo ele, essas línguas combinam no verbo as informações de movimento e percurso, ficando aos satélites (preposições e advérbios) a tarefa de expressar o modo (ou causa) do movimento, se ocorrer. A esse segundo grupo pertencem línguas como inglês, alemão, polonês, russo, chinês etc. Aqui, ao contrário, os verbos carregam a informação do modo do movimento e transferem aos satélites a idéia de percurso. Vejamos alguns exemplos (Talmy 2000b: 28):

(1) The rock slid down the hill. A pedra escorregou abaixo/para baixo de Wa colina. "A pedra escorregou colina abaixo"

(2) The bottle floated into the cave. A garrafa flutuou para dentro da gruta. "A garrafa entrou na gruta (flutuando)"

(3) The napkin blew off the table. O guardanapo soprou da/para longe da mesa. "O guardanapo caiu da mesa por causa do vento" ou "O guardanapo voou da mesa por causa do vento"

\footnotetext{
Os termos Figure e Ground foram adotados da Psicologia Gestalt, mas Talmy deu a eles uma interpretação semântica distinta: "The Figure is a moving or conceptually movable entity whose path or site is at issue. The Ground is a reference frame, or a reference object stationary within a reference frame, with respect to which the Figure's path, or site is characterized" (Talmy 2000b: 26).
} 
Nos exemplos (1) e (2), os verbos slide e float contêm, ao mesmo tempo, as noções de movimento e o modo como esse movimento é realizado: a pedra move-se escorregando, e a garrafa, flutuando. No exemplo (3), estão embutidas no verbo blow as idéias de movimento e causa: o guardanapo voa da mesa por causa da ação do vento, ainda que este não esteja expresso. As línguas que apresentam esse padrão são chamadas satellite-framed.

Os exemplos (4) e (5) abaixo ilustram o padrão verb-framed proposto por Talmy (2000b: 49-51):

$\begin{array}{llll}\text { (4) Esp. La botella entró } & \text { a la cueva } \\ \text { A garrafa entrou } & \text { na gruta } & \begin{array}{l}\text { flotando. } \\ \text { flutuando. }\end{array} \\ \text { (5) Esp. Metí el barril } & \begin{array}{l}\text { a la bodega } \\ \text { na adega }\end{array} & \begin{array}{l}\text { rodándolo. } \\ \text { rodando-o. }\end{array}\end{array}$

Nesses exemplos, a raiz do verbo expressa ao mesmo tempo o movimento e o percurso (ou caminho). Talmy (2003:49) afirma que as línguas românicas em geral pertencem a esse grupo. Nestes casos, se o modo ou a causa do movimento for expresso, será através de uma construção gerundiva ou adverbial, ao contrário do padrão satellite-framed, em que esse traço está na raiz do verbo.

Essa classificação gerou um grande número de trabalhos com críticas e propostas, defendendo que as línguas não se encaixam perfeitamente nessa divisão dupla de Talmy (cf. Zlatev \& Yangklang 2004, Sampaio et al. 2008, entre outros). Slobin (2004) propõe, por exemplo, uma terceira possibilidade, que dê conta de línguas com séries verbais, verbos genéricos e verbos bipartitivos: equipollently-framed. Nessas línguas, o modo do movimento e o percurso são expressos em formas gramaticais equivalentes.

Outros autores ora comprovam essa divisão, ora apresentam maior detalhamento em relação às diferenças entre as línguas. Ibarrexte-Antuñano (2004, 2008) mostra que as línguas basca e espanhola, ambas rotuladas verbframed por Talmy, diferem quanto à frequência de expressão do modo do movimento, ou seja, o basco traz mais frequentemente a informação sobre o modo do movimento que o espanhol. Além disso, segundo a autora, as informações de percurso são mais detalhadas em basco do que em espanhol. Em função disso, tem sido proposto um continuum de saliência do percurso (Ibarrexte-Antuñano 2004, 2008) e modo (Slobin 2004), em vez de inserir as línguas em categorias tipológicas. 
Cifuentes Férez (2008) oferece um estudo bastante detalhado do modo de movimento e percurso com verbos ingleses e espanhóis. Ainda que seu corpus limite-se a dicionários, sua análise quantitativa e qualitativa leva em conta a possibilidade de ambas as línguas apresentarem os padrões verb-framed e satellite-framed.

Em relação ao português, destacam-se os estudos de Batoréo (2008, 2006) e Pires (2007), em que as autoras analisam verbos que combinam a informação do movimento e do Ponto de Referência, especificamente aqueles que expressam movimento em água ( $A Q U A$-motion, nos termos das autoras). Esses estudos restringem-se a dados do Português Europeu, faltando, portanto, a análise para o Português Brasileiro. A presente pesquisa procurará preencher essa lacuna, ainda que de forma resumida.

Se voltarmos aos exemplos (1) a (5) expostos acima, veremos que o português admite ambos os padrões:

(1a) A pedra escorregou colina abaixo [SATELLITE-FRAMED]

(2a) A garrafa flutuou para dentro da gruta. [SATELLITE-FRAMED]

(3a) O guardanapo soprou da mesa (com o vento). [SATELLITE-FRAMED]

(4a) A garrafa entrou na gruta flutuando. [VERB-FRAMED]

(5a) Coloquei o barril na adega girando-o. [VERB-FRAMED]

(5b) Rolei o barril para dentro da adega. [SATELLITE-FRAMED]

Em função dessas possibilidades, é mais conveniente falar em tendências, em vez de uma classificação dicotômica. Lembremos também os verbos enter e exit do inglês: Talmy (2000b: 53) os exclui de sua classificação, por serem de origem latina e pouco usados em conversas espontâneas. Entretanto, são verbos correntes na língua escrita e diferem de entrar e sair quanto à estrutura. Em inglês, esses verbos não admitem nenhuma preposição:

(6) He entered the house.

"Ele entrou na casa".

(7) She exited the theatre.

"Ela saiu do teatro". 
2.1 Padrões de representação do movimento no Português Paulista

Os exemplos (6) e (7) acima nos levam a questionar de que forma o português pode construir expressões de mvoimento com os verbos entrar e sair. Abaixo, apresento alguns exemplos ${ }^{4}$ :

(8) [AI 1736 C19] Eu griteilhe eoPadre entrou aSella [a]buscar hu' faconete sem ponta, ...

(9) [M1 1734] Deste ponto fomos dormir distância de léguas junto a um córrego, que entra como os mais no Rio Grande.

(10) [M11 1918] ... a segunda parte [das terras] começando no rio de S.Vicente até doze léguas ao sul de Cananéia; nessas divisas indicadas deveriam ser postos padrões, com as armas reais, e deles correriam linhas diretas entrando para oeste pelo sertão adentro e terra firme, ...

(11) [AI 1804 C28] e enca-rregando igualmente amesma deligencia a Joâo de Campos e a Manuel Vâs, aquelle para entrar pelos Batataes athe alagôa

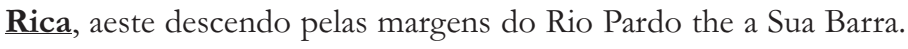

(12) [Seb 1785 C22] edis o dito picador que achou boa Saida para aSerra, elogo que sairaõ osditos meus picadores fis aviZo ao dito Capitam mor para ele entrar delá ComoCaminho

(13) [AI 1736 C19] ....agora mediSse hua India, que o Capitam da aldeia tinha ordem do Senhor Joseph para vegiar as Indias, que entraSsem dentro desta Casa alevar alguã couza, compena de Serem a Soutadas

(14) [M5 1788] Maio 13 - Saí de São Paulo e cheguei à Vila e Praça de Santos, fundada na margem meridional de uma espaçosa e limpa baía,

(15) [WL 1914 C16] E'coisa facil, com mais umas trez lições, eu o [chauffeur] dispensarei. Amanhá vou sahir na estrada.

(16) [M3-7 1797] Acontece neste rio o mesmo que se vê no Pará: As águas do Amazonas vão sair ao mar entre o cabo do Norte e a ilha de Joanes. Para sair-se ao Amazonas partindo da cidade do Pará, é necessário atravessar o rio Mojú, Capim e Tocantins ...

(17) [Seb 1721 C02] Oófisial olandes que veio aterra, prometeume desahir fora deste porto para odeSanctos aosvinte enove deste mes.

$4 \quad$ As siglas dos exemplos correspondem a: AI = Cartas de Aldeamentos de Índios (Simões \& Kewitz 2006a); WL = Correspondência Passiva de Washington Luiz (inédito); Seb = Cartas de Militares e Capitão-Mor de São Sebastião (Simões 2007); M = Memórias (v. bibliografia). 
Esses exemplos demonstram diversas possibilidades de combinação dos verbos entrar e sair encontrados em corpora dos séculos XVIII a XX. Quero chamar a atenção, no entanto, para a questão do redobramento do traço percurso com esses verbos. Nos exemplos (9) e (15), temos os verbos entrar e sair, respectivamente, seguidos da preposição em, e os exemplos (13) e (17) apresentam esses verbos combinados com as expressões dentro de e fora de, respectivamente. O esquema abaixo evidencia o redobramento do traço de percurso:
(a) entrar
em
MOVER-SE PARA DENTRO
DENTRO
(b) entrar
dentro de
MOVER-SE PARA DENTRO
DENTRO
(c) sair
fora de
MOVER-SE PARA FORA
FORA

Em (a), observa-se o redobro da noção "no interior de, dentro" na raiz do verbo (entrar) e na preposição em. O mesmo ocorre em (b), com a confluência desse traço no verbo e na preposição complexa dentro de. Com o verbo sair, o redobro só ocorre mediante a combinação com a preposição complexa fora de. Essas ocorrências não são estranhas ao falante de português (ainda que o redobro em entrar + dentro e sair fora seja estigmatizado), visto que preposições redobram o que já se vê nos prefixos, como em concordar com, comparar com etc. Moraes de Castilho $(2004,2005)$ constatou vários elementos redobrados, tais como clíticos, locativos, partículas negativas etc. no português medieval. No português atual, encontramos ocorrências do tipo en te disse pra você, desce lá embaixo, eston aqui em São Paulo, en não sei não, etc.

Com base na abordagem multissistêmica (Castilho 2007, 2010), hipotetizei que as razões para o percurso redobrado se devem a diversos fatores, alguns dos quais elenco a seguir: (i) desativação do sentido de base desses verbos, levando à ativação de outros elementos (como as preposições complexas) para expressar o percurso do movimento; (ii) reativação dos elementos que redobram o percurso com a função discursiva de ênfase; (iii) ativação de propriedades prosódicas, sobretudo com a presença de dêiticos, como em sobe lá em cima, saí lá fora, entra aqui dentro etc. Ressalta-se que esses princípios ocorrem simultaneamente, sem hierarquias (cf. Castilho 2007, 2010). 
Evidências como essas nos permitem afirmar que o redobramento implicaria numa outra classificação do português em relação ao padrão de lexicalização do percurso, ou seja, ele se apresenta no verbo e nas preposições ${ }^{5}$ (ou satélites, termos de Talmy).

Além disso, há diversos verbos que combinam as propriedades semânticas de movimento e o modo como esse movimento é realizado, como andar, rodar, caminhar, correr, desembarcar etc. Alguns exemplos para ilustrar:

(18) [M2 1738] Saídos deste mato passamos 7 campinas com belos pastos, distância de légua

e meia, e no fim delas o rio das Canoas que costuma ser o desembarque dos que rodam de Curitiba pelo rio grande abaixo.

(19) [M1 1734] Caminhamos rio abaixo e depois d'alguns dias nos quebrou a outra Canoa.

(20) [M9 1900] Quando pela primeira vez desembarquei em Folkstone, entrando na Inglaterra, eu tinha passado meses em Paris...

Talmy (2000b) elenca, além dos dois padrões de combinação descritos acima, outros menos frequentes, mas que não configuram o padrão central de nenhuma língua, segundo ele. Vejamos:

(a) Movimento + Co-Evento (Modo, Causa etc.): confluência do movimento com o modo ou a causa desse movimento: flutuar, andar, correr etc.

(b) Movimento + Percurso: combinação do movimento e de seu percurso no verbo: entrar, sair, subir, descer, ir, voltar etc.

(c) MOVIMENTO + FIGURA: confluência do movimento com alguma parte da Figura: cbutar (movimento feito pelos pés da Figura); cuspir, acotovelar, cabecear, manusear etc.

(d) Movimento + Ponto DE REFerêNCIA (PR): confluência do movimento com alguma parte do PR. O autor afirma que essa combinação não corresponde ao padrão central de nenhuma língua, e os exemplos são raros: (ingl.) enhouse, dehouse, emplane, deplane, cujas bases são respectivamente bouse e plane (op. cit., 2000b: 60-61).

5 Em Kewitz (2010), denominei esse padrão double path ou percurso redobrado. 
(e) Movimento + 2 ou mais Componentes SEMÂnticos: assim como (c) e (d), esse padrão não forma o sistema principal de lexicalização do movimento, segundo o autor.

Depreende-se que a pergunta principal de Talmy (2000b) é saber se todas essas possibilidades configurariam o padrão central de uma dada língua, ou seja, ainda que ela apresente outras possibilidades, sua base será ou (a) ou (b), satellite-framed ou verb-framed, respectivamente.

Cifuentes Férez (2008) apresenta uma classificação bastante interessante para verbos do inglês e do espanhol. A autora insere em (d) acima verbos que Talmy colocaria em (e), tais como costear (navegar pela costa), voar (mover-se pelo ar), bordear (mover-se pela borda), abeirar (mover-se pela beira) ${ }^{6}$ etc. Por ser uma classificação mais refinada e aplicada a dados do espanhol, optei por basear minha análise na classificação de Cifuentes Férez. Para (e), a autora apresenta as seguintes possibilidades:

(e1) MOVIMENTO + PERCURSO + MODO: escapar, fugir, invadir, trepar etc.

(e2) MOVIMENTO + PERCURSO + PR: embarcar, desembarcar, nanfragar, imigrar, vadear etc.

(e3) MOVIMENTO + MODO + PR: nadar, mergulhar, revoar etc.

(e4) MOVIMENTO + FIGURA + MODO: pisar, pisotear, espernear etc.

(e5) MOVIMENTO + FIGURA + CO-MOVIMENTO: acompanhar, guiar, escoltar.

Os padrões elencados em (a)-(e) e (e1)-(e5) distribuem-se de maneira não uniforme nas línguas, e o mesmo vale para o português. Em dados coletados de memórias e de cartas diversas nos séculos XVIII a XX, pode-se perceber a riqueza e a complexidade presentes nas expressões linguísticas. Na tabela 1 abaixo, apresento alguns resultados quantitativos de dados coletados em 4000 palavras a cada 50 anos de século em cada tipo de texto. Os exemplos para cada categoria são apresentados logo após a tabela.

${ }^{6}$ Exemplos adaptados para o português. 
Tabela 1: Distribuição dos padrões de representação do movimento por tipo de documento e século

\begin{tabular}{|c|c|c|c|c|c|c|c|}
\hline & \multicolumn{2}{|c|}{ XVIII } & \multicolumn{2}{|c|}{ XIX } & \multicolumn{2}{|c|}{ XX } & \multirow{2}{*}{ total } \\
\hline & Memórias & Cartas & Memórias & Cartas & Memórias & Cartas & \\
\hline $\mathbf{M}$ & 2 & 0 & 1 & 0 & 0 & 0 & 3 \\
\hline $\mathbf{M}+\mathbf{P}$ & 103 & 43 & 35 & 27 & 19 & 17 & 244 \\
\hline $\mathbf{M}+\mathbf{M o}$ & 32 & 2 & 10 & 2 & 3 & 2 & 51 \\
\hline $\mathbf{M}+\mathbf{P R}$ & 2 & 0 & 0 & 0 & 1 & 0 & 3 \\
\hline $\mathbf{M}+\mathbf{P}+\mathbf{P R}$ & 9 & 2 & 2 & 0 & 2 & 1 & 16 \\
\hline $\mathbf{M}+\mathbf{P}+\mathbf{M o}$ & 10 & 5 & 5 & 0 & 0 & 1 & 21 \\
\hline $\mathbf{M}+\mathbf{M o}+\mathbf{P R}$ & 1 & 0 & 0 & 2 & 0 & 0 & 3 \\
\hline $\mathbf{M}+\mathbf{P D}$ & 0 & 1 & 0 & 0 & 0 & 1 & 2 \\
\hline Outras & 3 & 11 & 2 & 2 & 2 & 0 & 20 \\
\hline total & 162 & 64 & 57 & 31 & 27 & 22 & 363 \\
\hline
\end{tabular}

Legenda:

$\mathbf{M}=$ Movimento

$\mathbf{P}=$ Percurso

Mo $=$ Modo do Movimento

$\mathbf{P R}=$ Ponto de Referência

PD $=$ Percurso redobrado

Os resultados da tabela 1 acima precisam ser analisados com algumas ressalvas: (i) o recorte privilegiou um número limitado de dados (em 4000 palavras); (ii) a tipologia textual, aqui apresentada amalgamada, revela traços distintos de um século a outro, a exemplo das memórias e diários de viagem e dos tipos de cartas ao longo dos séculos; (iii) a dificuldade em separar quando um verbo codifica e quando implica certos traços semânticos, como os relacionados na tabela; e (iv) a interpretação que se dá aos dados baseia-se em nosso conhecimento de leitores contemporâneos. Dito isso, pode-se depreender que o padrão MOVIMENTO + PERCURSO é mais frequente, com 244 dados nos três séculos. No entanto, a presença de ocorrências de dados das demais combinações não permite classificar o português como uma língua exclusivamente verb-framed. Apresento abaixo alguns exemplos encontrados nos corpora:

MOVIMENTO

(21) 17 - Tendo andado 3 léguas, deixamos a boca do rio Urubuçuará, e no fim de 5 mudamos para o rumo de $\mathrm{SSO}$ e vimos muito ao longe

Números absolutos de dados. 
a outra margem do Amazonas. [Diário de Viagem, 2. ${ }^{a}$ metade do XVIII]

MOVIMENTO + PERCURSO

(22) Resolvi não voltar mais para o Guarujá. [Corresp. Passiva Washington Luiz, 1900, Carta 10]

MOVIMENTO + MODO

(23) Uma das primeiras vítimas veio a ser o próprio e infeliz chefe, falecido à margem do rio Negro. Afinal, arrastando-se penosamente, conseguiu atingir a povoação de Miranda a 396 quilômetros para o Sul. [Memória, Taunay, 1867]

MOVIMENTO + PONTO DE REFERÊNCIA

(24) Setembro 16 - Pela uma hora da noite, deixando o rio Tapajós, seguimos viagem costeando a margem setentrional da grande ilha Paricatuba, ... [Diário de Viagem, 2. ${ }^{\text {a }}$ metade do XVIII]

\section{MOVIMENTO + PERCURSO + PONTO_DE_REFERÊNCIA}

(25) onde se concentram todos os recursos do Brasil, como ainda por causa das inundações do rio Paraguai, que, cortando na parte superior do curso terras baixas e planas, transborda anualmente, a submergir então regiões extensíssimas. [Memória, Taunay, 1867]

MOVIMENTO + PERCURSO + MODO

(26) ConSsigo poCo fruto aSSim por alguñs fugirem deSSua aldea; [Cartas de Aldeamento de Índios, 1722, Carta 03]

MOVIMENTO + MODO + PONTO_DE REFERÊNCIA

(27) Tal injunção, no ponto a que chegáramos, impunha como forçado corolário obrigar-nos a descer em direção ao rio coxim e a contornar em seguida a serra de Maracaju, [Memória, Taunay, 1867]

\section{MOVIMENTO + PERCURSO REDOBRADO}

(28) Como tão bem ordenão oque seade fazer aos que sai fora ganhar. [Cartas de Aldeamento de Índios, 1783, Carta 22] 


\section{OUTRAS COMBINACÕES}

Aqui inserem-se exemplos de combinação entre MOVIMENTO e FIGURA, entre outros elementos, no verbo:

(29) Uma terceira se dirigia até Franca seguindo o curso do famoso Caminhos dos Guaiases, que conduzia às minas de Goiás após atravessar o Triângulo Mineiro. [Memória, 2. ${ }^{a}$ metade do XX, Terra Paulista]

Cada uma dessas combinações mereceria um refinamento na análise, sobretudo quando lidamos com dados de sincronias passadas. Nesse caso, a diversidade de tipologia textual será de primordial relevância, uma vez que cada tipo de texto faz surgir determinadas estruturas atreladas aos objetivos comunicativos específicos desse texto. Trato desse aspecto no item 3 no que concerne às mudanças de tradições discursivas das memórias e das cartas.

\subsection{Pontos do Percurso no Português Paulista}

Nesta seção, analiso estruturas que representam o deslocamento no espaço físico, tendo sido completado ou não. Nesta etapa da pesquisa, decidiu-se selecionar dados em 1000 palavras de cada tipo de texto, para cada 50 anos dos séculos XVIII a XX. Esse recorte foi necessário em função dos seguintes fatores: (a) não há equilíbrio em relação aos corpora, visto que, por exemplo não há inquéritos orais ou jornais no século XVIII, (b) dentro do mesmo gênero (memórias, por ex.), constatam-se mudanças de tradições discursivas, (c) vários corpora encontram-se ainda em fase de coleta e/ou edição.

Alguns autores afirmam que há uma tendência à codificação do ponto final do percurso em detrimento dos demais (inicial e medial). Esse fenômeno tem sido descrito em termos de windowing of attention e gapping: Talmy (2000a). Trata-se da seleção de uma determinada parte do evento, direcionando a ela maior atenção (foregrounding), deixando outras partes em segundo plano (backgrounding). Na língua, a atenção é realizada pela inclusão de expressões lingüísticas colocadas em relevo, e as partes em segundo plano correspondem às expressões excluídas. Ainda que apenas uma determinada parte da cena ou evento seja colocada em relevo pelo falante, o processo cognitivo da atenção possibilita que o ouvinte infira ou pressuponba o restante da cena, aquilo que está em segundo plano. 
Talmy (2000a) propõe que os eventos de movimento incluem necessariamente uma Figura, um Objeto de Referência, o movimento em si e o percurso a ser traçado pela Figura, conforme exposto na seção anterior. Porém, esses quatro elementos não precisam estar presentes, ou seja, podem ou não estar codificados. Para ilustrar como um percurso pode ser descrito em função da atenção, vejamos os seguintes exemplos:

(30) A caixa que estava no porão de carga caiu do avião pelo ar para dentro do oceano. ${ }^{8}$

(31) A caixa que estava no porão de carga caiu no oceano.

(32) A caixa caiu do avião.

(33) A caixa caiu.

Nos quatros exemplos, a cena é a mesma. Porém, cada descrição privilegia uma porção desse evento: em (30), a atenção volta-se a todos os pontos do percurso, ao passo que em (31), apenas o ponto de chegada da Figura, e em (32) seu ponto de partida. Em (33), apenas a idéia de movimento é expressa, ficando o restante omitido, podendo ser inferido pelo contexto e pelo conhecimento de mundo, isto é, pela noção que temos da força da gravidade.

O processo de relevo ou omissão da atenção que atua nos eventos é parte fundamental da estruturação conceitual no sistema cognitivo humano de comunicação (Talmy 2000a). Os dois processos são complementares e necessários, pois a omissão de elementos dá lugar à atenção sobre outros elementos, sejam quais forem suas motivações: redundância, repetição, menor relevância, obviedade - todos podem ser preenchidos pelo ouvinte (cf. Talmy 2005).

Stefanowitsch \& Rohde (2004) investigam as motivações por trás da distribuição da atenção em dados do inglês (coletados em corpora de notícias americanas), a partir de duas hipóteses:

\footnotetext{
(a) bipótese da saliência (psicológica): proposta por Verspoor, Dirven \& Radden (1999, apud Stefanowitsch \& Rohde 2004: 251), baseia-se na tendência natural do ser humano em relação a metas, objetivos, pois toda ação humana envolve volição, tendendo, portanto à meta da ação, mais do que sua fonte.
}

8 Adaptado de Talmy (2000a: 266): "The crate that was in the aircraft's cargo bay fell out of the plane through the air into the ocean". 
(b) hipótese da conceptualização completa: proposta por Ungerer \& Schmidt (1996, apud Stefanowitsch \& Rohde 2004: 252), refere-se à conceptualização do percurso como um todo. A codificação do ponto final possibilita recuperar informações de todo o percurso, ao passo que os demais pontos não. Por outras palavras, se sabemos qual é o ponto de chegada, podemos inferir sobre os demais pontos da trajetória.

Para verificar essas hipóteses, Stefanowitsch \& Rohde (2004) classificam os dados em quatro grupos ${ }^{9}$ em função do tipo de verbo, animacidade da Figura, presença ou ausência de sintagmas preposicionados, direcionalidade inerente em determinados verbos, dentre outros fatores. As duas hipóteses puderam ser confirmadas, não como regra absoluta, mas como tendência. Há casos em que o ponto final do percurso não é codificado, mas inferido, ora pelo contexto, ora pelo conhecimento de mundo (ex.: He fell from the roof: sabese que o ponto final é o chão pelo conhecimento que temos da força da gravidade). Além disso, há verbos que não exigem a marcação do ponto final, tais como escape (SP-fonte) ou stroll ${ }^{10}$ (SP-ponto medial). Se a conceptualização do deslocamento não inclui a codificação de um ponto final é porque simplesmente não é necessário (ou porque é inferido, conforme explicitado acima). Segundo os autores, eventos são o resultado da segmentação cognitiva de um processo contínuo que constitui nossa realidade. A tendência à marcação do ponto final é mais uma questão de prototipicidade, sem invalidar as afirmações contidas nas hipóteses descritas acima, isto é, que o ser humano tende a marcar o ponto final do percurso por estar mais interessado no objetivo da ação etc. (cf. Stefanowitsch \& Rohde 2004: 265).

Relações entre estrutura conceptual e linguística são complexas, multidimensionais e, portanto, passíveis de motivações diversas: Castilho (2007, 2010), Stefanowitsch \& Rohde (2004).

Nesta pesquisa, os pontos do percurso considerados forma: inicial, medial e final, além da categoria vazia e de combinações (inicial + final, inicial + medial, medial + final etc.) A tabela abaixo mostra o percentual geral dos pontos do percurso dos séculos XVIII, XIX e XX.

9 Por questões de espaço, não apresento aqui essa classificação e a forma como os autores chegaram aos resultados.

10 Stroll = Caminhar lentamente de forma relaxada, geralmente por prazer. 
Tabela 2: Distribuição dos pontos do percurso (séculos XVIII-XX)

\begin{tabular}{|l|c|c|c|c|c|c|}
\hline & INICIAL & MEDIAL & FINAL & $\varnothing$ & COMBINAÇÕES & TOTAL \\
\hline N. & 45 & 46 & 170 & 72 & 48 & 381 \\
\hline$\%$ & $11,81 \%$ & $12,07 \%$ & $44,62 \%$ & $18,90 \%$ & $12,60 \%$ & $100 \%$ \\
\hline
\end{tabular}

Esses resultados se assemelham aos encontrados por Stefanowitsch \& Rohde (2004) em relação à tendência de codificação do ponto final do percurso. Porém, ressalto que nessa tabela estão os dados de língua escrita (comum aos três séculos) e de língua falada (apenas século XX). Por exemplo, do número de casos de categoria vazia, 35 são de textos escritos, e 37 advêm dos inquéritos orais. Vejamos como se distribuem esses dados em cada século e tipo de texto.

Tabela 3: Distribuição dos pontos do percurso por tipologia textual no século XVIII ${ }^{11}$

\begin{tabular}{|l|r|r|r|r|r|c|}
\hline & Inicial & Medial & Final & $\varnothing$ & $\begin{array}{c}\text { combina } \\
\text {-ções }\end{array}$ & total \\
\hline Cartas oficiais & 7 & 0 & 18 & 3 & 0 & $\mathbf{2 8}$ \\
\hline Cartas de Administração Privada & 6 & 2 & 11 & 5 & 0 & $\mathbf{2 4}$ \\
\hline Memórias e Diários de Viagem & 10 & 11 & 22 & 11 & 14 & $\mathbf{6 8}$ \\
\hline total & $\mathbf{2 3}$ & $\mathbf{1 3}$ & $\mathbf{5 1}$ & $\mathbf{1 9}$ & $\mathbf{1 4}$ & $\mathbf{1 2 0}$ \\
\hline
\end{tabular}

A tabela acima mostra que o ponto final do percurso é o mais frequente nos textos do século XVIII, seguido do ponto inicial. Os demais pontos distribuem-se praticamente de forma equilibrada, considerando o total de dados para esse século. A categoria vazia representa, geralmente, o ponto final, que pode ser recuperado pelo contexto. Exemplo:

(34) Eoutro Ssim por que hay huãs profeçias de Como vossaexelencia naõ hade hir a Cujaba

SenoSso Senhor ouvir osRogos dospeccadores aSsim mesmo hadeSer por que me parece naõ ha’ quem Sedescuide Com esta deligençia inda que Seria

11 Os dados das tabelas 3 a 5 são em número absoluto. 
Com muito dispendio de vosaexdendia Seadita profeçia sahir Certo eu Sobre todos devo Ser o mais Contante por ficar

Soçegado mas Suponho indo vossaexelencia Sempre ficarei aSombra dos Criados devosa ex dencia (Carta de Administração Privada, Aldeamento deÍndios, Carta 11, 1726: Simões \& Kewitz (2006a), meus grifos))

O trecho em negrito mostra a ausência do ponto final do (suposto) percurso de vossa excdência. Mas é inferido a partir do que foi expresso antes: Cuiabá, no trecho sublinhado. De maneirageral, dados como esses são bastante recorrentes nos três séculos e em todos os tipos de texto.

Ao observarmos o resultado para cada tipo de texto, vemos algumas diferenças que merecem atenção. As descrições espaciais encontradas nas memónias e diánios de viagem do século XVIII são riquíssimas e detalhadas. Isso se dá em função dos objetivos desses textos, sobretudo no XVIII: explorar, conhecer e descrever lugares no Brasil, em busca de ouro e outras niquezas, índios etc. Essa missão devia ser reportada a um supenior na corte portuguesa durante a colônia. Alguns exemplos:

(35) - Mas antes de passar adiante darei uma breve relação da origem e situação de Vila Bela, de onde parti neste dia para a do Cuiabá pelo caminho de terra, e dos nios que banham os seus territónios, das suas produções, etc. (Francisco José Lacerda e Almeida: Diánio de Vila Bela atéa Cidadede São Paulopela derrota ordinánia dosnios 1788-1790)

(36) Passado o rio Theaté fomos pousar neste dia junto ao mato do Jundiaí, quatro léguas distante da Cidade de São Paulo; (José Peixoto da Silva Braga: Notícia - 1a Prática

- Que a da ao P. Me de Diogo Soares o Alferes José Peixoto da Silva Braga, do que passou na Primeira Bandeira, que entrou ao descobrimento das Minas do Guayases até sair na Cidade do Belém do Grão-Pará. 1734)

As cartas de administração pública e privadaapresentam menos descrições espaciais como as encontradas nas memónias e diánios. Além disso, são menos complexas, considerando a ausência de combinações e a baixa frequência dos pontos inicial e medial do percurso em relação ao ponto final. Observações como essas podem estar associadas ao objetivo das cartas: relatar algum fato ou a situação local de maneira breve com vistas a que seu supenior tome as devidas providências. Exemplo: 
(37) OS[oplicante] Padre Joaõ Barboza deSumCam Sendo Naturar Naferguezia dejavari PaSou Acazade Naoscal dacompanha torio verde onde Tem deSua Molher dois filhos edeixando a[ela?] jasfilhos vortou Para Asua patria freguzia dejauari onde Rezidio Algus Annos (Carta Oficial, Militares Comandantes - Capitão Mór de Bragança, Atibaia e Naz̧aré, Carta 6, 1797: Simões 2007)

Algumas cartas de administração privada (do conjunto Aldeamento de Índios) relatam, às vezes, o deslocamento do habitantes das aldeias detalhadamente, sobretudo quando o episódio refere-se à fuga de índios. Essas cartas vêm geralmente com reclamações de quem escreve, diferentemente das memórias e diários. Exemplos:

(38) concervava o Suplicante para oreferido, hú rapas deNome Francisco, oqual induzido por Francisco de Figueiró ta-verneiro destaCidade, fugio do Suplicante edezertou aAldea (Carta de Administração Privada, Aldeamento de Índios, Carta 23, 1788: Simões \& Kewitz 2006b)

Os documentos do século XIX distribuem-se entre textos extraídos de jornais, cartas oficiais e pessoais e memórias históricas. Vejamos os resultados:

Tabela 4: Distribuição dos pontos do percurso por tipologia textual no século XIX

\begin{tabular}{|l|c|c|c|c|c|c|}
\hline & Inicial & Medial & Final & $\varnothing$ & $\begin{array}{c}\text { combina } \\
\text {-ções }\end{array}$ & total \\
\cline { 2 - 7 } & \multicolumn{7}{|l|}{} \\
\hline Cartas oficiais & 1 & 0 & 4 & 2 & 0 & 7 \\
\hline Cartas de leitores de jornais & 2 & 8 & 9 & 2 & 1 & $\mathbf{2 2}$ \\
\hline Anúncios de jornais & 3 & 1 & 19 & 0 & 2 & $\mathbf{2 5}$ \\
\hline Cartas pessoais & 1 & 4 & 15 & 7 & 1 & $\mathbf{2 8}$ \\
\hline Memórias & 3 & 7 & 6 & 0 & 10 & $\mathbf{2 6}$ \\
\hline \multicolumn{7}{|l|}{} \\
\hline total & $\mathbf{1 0}$ & $\mathbf{2 0}$ & $\mathbf{5 3}$ & $\mathbf{1 1}$ & $\mathbf{1 4}$ & $\mathbf{1 0 8}$ \\
\hline
\end{tabular}

Novamente, os dados que codificam o ponto final do percurso apresentam-se em maior número, seguidos do ponto medial. As memórias equilibram a representação dos pontos medial e final, mas o número de combinações 
entre pontos é maior, ao contrário do que se observa para o século XVIII. Alguns exemplos:

(39) Tambem vi alguns pedaços de porfido verde, cu_jo jazigo ignoro, eoutros de opal commum muito semilhante ade_Telka[b]onia na Hungria, penetrada toda de calcedonia branca, queme disse o Administrador achar-se em beta atravessando o gra_nito. (Memória de José Bonifácio, 1820: Simões 2007) [PONTO MEDIAL]

(40) Assim, pois, estava a expedição condenada a atravessar extensíssíma região empestada pelas febres palustres. (Memória histórica, Visconde de Taunay, 1867: Simões 2007) [PONTO MEDIAL]

(41) Assim se adiantou em direção ao noroeste, até as margens do Paranaíba, quando ali recebeu peremptórias ordens do governo, levando-lhe instruções formais de marchar para o distrito de Miranda, então ocupado pelo inimigo. (Memória histórica, Visconde de Taunay, 1867: Simões 2007) [PONTO FINAL]

(42) Consistia o plano de ataque mais natural em subir as águas do Paraguai, do lado da Argentina, até o coração da república inimiga e, do Brasil, descê-las a partir de Cuiabá, a capital mato-grossense que os paraguaios não haviam ocupado. (Memória histórica, Visconde de Taunay, 1867: Simões 2007) [COMBINAÇÃO]

Os poucos dados nas memórias do XIX, comparando-se aos dados do XVIII, devem-se à tarefa comunicativa dos dois textos selecionados para este período. O da primeira metade do XIX foi escrito por José Bonifácio a respeito da fábrica de ferro Ipanema em Sorocaba, em que ele descreve o trabalho de extração e a qualidade do minério, o que propicia o uso de descrições, mais que narrativas. $\mathrm{O}$ texto da segunda metade refere-se à formação de um corpo de exército destinado a atuar na Guerra do Paraguai, escrito por Visconde de Taunay. Ambas as memórias apresentam um núcleo temático bem distinto daquele presente nos textos do XVIII. Além disso, têm um caráter mais informativo e histórico, sem que necessariamente fossem destinadas a um superior dando contas de sua missão.

As cartas pessoais apresentam alta frequência de categoria vazia, da qual apenas um caso refere-se ao ponto inicial (exemplo 43); o ponto final é inferido nos demais casos (exemplo 44): 
(43) Tenho plena certeza que si aqui ficassemos um anno sem sahir, nossas finanças melhorariam mui-to e muito; infelismente porem, por mais que faça nada consigo nesse sentido. (Carta particular a Washington Luiz, 1900, carta 16: Simões \& Kewitz 2006a)

(44) Estamos aqui desde o dia 31 do proximo passado eu Elisa Zé e, Tonica, da’hi a tres dias chegou Chiquinho com familia a qual ainda aqui está, elle seguio para São Paulo antes de hontem, e esperamos com Joaô depois de amanha, quarta feira, e anciosa espero a dele 20, afim de abraçar a voces, o Alvaro tambem pretende vir nesse dia. (Carta da sogra a Washington Luiz, 1900, Carta 19: Simões \& Kewitz 2006a)

Os anúncios de jornais do XIX tinham como objetivo divulgar produtos, serviços e fuga de escravos. Ao contrário das cartas pessoais, aqui a categoria vazia não aparece, uma vez que o local onde tais produtos e serviços eram encontrados deveria ser descrito com precisão. Nesse caso, a marcação do ponto final do percurso se faz necessária, comprovando a "hipótese da saliência" de Verspoor, Dirven \& Radden (1999, apud Stefanowitsch \& Rohde 2004: 251), que destaca a tendência natural do ser humano a expressar metas / objetivos. Exemplo:

(45) VENDA DE UM SITIO E ESCRAVOS EM CAPIRARY Vende-se o sitiodenominado - Santa Anna, no municipio de São João de Capivary, distante legua e meia da cidade e junto ao caminho que vao para a villa de Santa Barbara, com cento e tantos alqueires de terra, cafezaes novos e velhos, casa de morada e outras bemfeitorias e mais cinco escravos, tres homens e duas mulheres, do serviço da roça Trata-se com o advogado doutor A. Gordo naquella cidade. (Anúncio do jornal Gazeta de Piracicaba, 1883: Guedes \& Berlinck 2000)

As cartas de leitores de jornais do XIX apresentam certo equilíbrio no número de dados dos pontos medial e final do percurso (8 e 9 , respectivamente). A tarefa comunicativa desse tipo de documento centrava-se em reclamar de problemas da cidade e de pessoas, criticar políticos, exigir providências para melhorias das ruas etc. São textos carregados de exageros, metáforas e

12 Para mais detalhes sobre as Tradições Discursivas das cartas de leitores de jornais do século XIX, v. Castilho da Costa (em preparação). 
exaltações. As narrativas ocorrem geralmente como efeito de $\operatorname{argumentação~}{ }^{12}$. Exemplo:

(46) Senhores Redactores. Não posso deixar de queixar-me á Vossas mercếs e ao publico do abandono, em que se acha a estrada, por onde costumo transitar com minha tropa. No tempo dos Presidentes, que eu ouvia chamar espumas, e arribados, e contra quem tanto se disse, e escreveo, achava se a estrada de Jundiahy á esta Cidade no melhor estado possivel, e nunca esteve ella tão boa, como em 1838 e 1839 quando governava a Provincia um Presidente, que dizião seus opposicionistas, não curava do melho-ramento da Provincia: hoje porem que não a go-verna um espuma ou arribado, mas sim um de seus adversarios chefe do partido chamado pau-lista, e á quem tantos elogios incessantemente fa-zem aquelles mesmos, que contra seus antecesso-res só tinhão insultos, e injurias a dirigir, acha-se aquella estrada no mais deploravel estado; pon-tes cahidas, pantanos, caldeirões, é o que n'ella se observa; entretanto Sua Excelência o Senhor Presidente parece que nem ao menos sabe, que tal é o estado d'essa estrada, por onde diariamente tantas tropas transitão! De meado do anno passado pa-ra cá duas ou tres viagens tenho feito, e nada de concertos, e a estrada arruinando se cada vez mais, de maneira que está hoje quasi intrasitavel. (Carta ao jornal A Phenix do leitor "Um tropeiro paulista", 1841: Barbosa \& Lopes Orgs.2006)

Os textos no século XX são mais diversificados em termos de tipologia, sobretudo pelo advento do gravador, possibilitando registros reais de língua falada. Além disso, especialmente a partir da segunda metade do século, as profissões se segmentam e se especializam (passam a existir publicitários responsáveis pelos anúncios e comerciais, revisores de texto, historiadores que dissertam cientificamente sobre um tema, e assim por diante). Não se pode esquecer também que os textos publicados em jornais e revistas passam pelo crivo do editor e da revisão, ao contrário do que se observa no XIX. A tabela 5 mostra os números de dados por tipo de texto, divididos em língua escrita e língua falada. 
Tabela 5: Distribuição dos pontos do percurso por tipologia textual no século XX

\begin{tabular}{|c|c|c|c|c|c|c|c|}
\hline \multirow{2}{*}{\multicolumn{2}{|c|}{$\begin{array}{l}\text { Cartas de leitores de jornais / } \\
\text { revistas }\end{array}$}} & Inicial & Medial & Final & $\varnothing$ & $\begin{array}{l}\text { combina- } \\
\text { ções }\end{array}$ & total \\
\hline & & 0 & 4 & 6 & 2 & 1 & 13 \\
\hline \multicolumn{2}{|c|}{ Anuncios de jornais } & 2 & 1 & 3 & 1 & 0 & 7 \\
\hline \multicolumn{2}{|c|}{ Cartas pessoais } & 1 & 0 & 7 & 2 & 3 & 13 \\
\hline \multirow{2}{*}{\multicolumn{2}{|c|}{ Memórias }} & 2 & 4 & 5 & 0 & 13 & 24 \\
\hline & & 5 & 9 & 21 & 5 & 17 & 57 \\
\hline \multirow[t]{3}{*}{ NURC } & D2 & 2 & 1 & 12 & 4 & 0 & 19 \\
\hline & DID & 0 & 0 & 13 & 11 & 0 & 23 \\
\hline & $\mathrm{EF}$ & 0 & 0 & 1 & 1 & 0 & 2 \\
\hline \multicolumn{2}{|c|}{ Filoband / Popular } & 5 & 3 & 19 & 21 & 3 & 51 \\
\hline & total parcial & 7 & 4 & 45 & 37 & 3 & 96 \\
\hline & total geral & 12 & 13 & 66 & 42 & 20 & 153 \\
\hline
\end{tabular}

Observa-se que o ponto final do percurso continua sendo o mais frequente no total geral de dados e em grande parte dos tipos de textos. Nos inquéritos orais de falantes semi ou não escolarizados (Filoband / Popular em $S P)$ e de falantes cultos (NURC - DID), vê-se um certo equilíbrio entre a codificação do ponto final e da categoria vazia. O núcleo temático de cada um desses inquéritos é fixo e dá margem a repetições (dos mesmos verbos e expressões), ora expressando, ora omitindo o ponto do percurso. Exemplos:

(47) Inf éh irmã dela e e um professor da faculdade aí de São::São Caetano do Sul...éh::ele dá aula::...no Serviço Social...e ele::nos convida de quase todo domingo a gente vai...eu tenho ido::bastante...prefiro ir a teatro do que a cinema...quando o filme não é bom né? (NURC, DID, SP, 1974: Preti \& Urbano 1988)

(48) Inf. tem o onibus qui leva...num passa aqui...pega lá imbaxu...na pedra grandi...é essi qui mai nói pricisava cumu eu falo pra elis...esse qui nóis pricisava que o ombe viesse pelo menu té aqui...i foi feitu abaxu sinadu pra vim até aqui...mai: :: aí acertô aconteceu nu sei o que cu marido da muié...a muié foi imbora nu vortô mai...á parô nu: :: veio cu onibus...pricisava vim até aqui é obrigação dele vim... a: :: tem uma netinha ali embaxo (a cida) fa/falô pa senhora...cuitadinha maGRInha piquiniNInha sai cedinho sem café qui nu toma café...batê até a hora da...da 
comida cuitadinha ia batê daqui lá andando...na pedra grandi...isso nu é moleza...eu falei u prefeitu faiz tantas coisa isso ele é obrigado a fazê uma coisa disso...paga mai uai...quem: :: pircisa andá no onibu paga mais um poquinho nu é nada mai...pagá mai não fazê judiera coitada da minina vai im jijum...que a coitadinha nu toma café...tadinha vai sem nada () até chegá na seti vorta istudá lá pa dispoi comê quarqué coisa nu é moleza (Filoband, Inq. 2)

Dentre os textos escritos, as memórias continuam apresentando maior número de dados de deslocamento no espaço. Dos 24 casos, 13 são combinações dos pontos do percurso, superando a codificação do ponto final. Exemplo:

(49) Existe também o Furado do Saboó, que é um pequeno esteiro que comunica os municípios da Conceição de Itanhaem e São Vicente com o de Santos, e por ele são transportados os produtos agrícolas daqueles municípios para o mercado de Santos. (Reminiscências de Santos, João Luís Promessa, 1930, ms. ${ }^{13}$ )

Em (49), o deslocamento expresso pelo verbo transportar completa-se pelos pontos inicial (daqueles municípios), medial (por ele [esteiro]) e final (para o mercado de Santos). A respeito dessa memória em especial, vale ressaltar que foi escrita a partir de outros textos, como documentos manuscritos de épocas anteriores, memórias etc. Essa forma de escrever memórias talvez propicie o uso de expressões espaciais mais detalhadas. O distanciamento do local e dos fatos descritos pode ser um fator relevante nesse caso. Diferentemente das memórias do século XVIII, esta do XX tem como objetivo preservar a história da cidade de Santos, tendo sido aprovada por um eclesiástico. A sobreposição de tradições discursivas demonstra, no entanto, que a forma de descrever o espaço, estático e dinâmico, foi aqui mantida.

Quanto às cartas particulares, as do XX assemelham-se às século XIX no número de dados do ponto final. Porém, elas apresentaram menor quantidade de expressões de deslocamento, se levarmos em conta o número de páginas: as do XX são mais extensas que as do XIX, o que nos faria supor justamente o contrário.

13 A edição filológica desse texto foi elaborada por Cláudia Damião Silveira, em sua tese de doutorado (2009, Faculdade de Filosofia, Letras e Ciências Humanas, Universidade de São Paulo). 
Os textos de jornal no XX diferem bastante do XIX no que diz respeito à extensão, linguagem e tarefa comunicativa. O pouco número de dados encontrados pode estar relacionado à tecnologia, ou seja, um anúncio ou comercial de hoje tem uma gama de recursos visuais que antes não havia, podendo aparecer, por exemplo, um mapa com a rota para se chegar à loja. Esse recurso pode ou não vir acompanhado de texto, mas em muitos casos apenas a figura já é suficiente.

As cartas de leitores nos jornais de hoje passam por edição e revisão, podendo muitas delas serem reduzidas (em relação ao original que chegou à mão do editor), diferentemente do que se vê nas cartas do XIX.

\section{Discursivização do movimento}

$\mathrm{Na}$ seção anterior, foram examinadas as propriedades semânticas das expressões espaciais de movimento no Português Paulista nos séculos XVIII a XX. Já ali apontei algumas caracterizações dos textos que serviram de base para a coleta de dados, sempre separando-os pela tipologia textual. Essa forma de lidar com dados de sincronias passadas baseia-se no modelo de Tradições Discursivas e nos trabalhos de Simões \& Kewitz (2006b, 2009a,b,c), Simões (2007) e Kewitz (2007). Nesta seção, aprofundo um pouco mais essa questão.

Para cada um dos pontos examinados na seção anterior, selecionei determinados gêneros, cujos dados foram coletados não exaustivamente, mas por número de palavras por gênero e por metade de século. Apresento a seguir os corpora dos séculos XVIII a XX utilizados na pesquisa, com uma breve descrição:

\section{Textos escritos:}

Cartas: divididas em cartas oficiais, cartas de administração privada e cartas particulares (ou pessoais) ${ }^{14}$, cada tipo apresenta características textuais específicas em função dos objetivos que fizeram surgir o texto e do grau de intimidade entre os escritores. Algumas delas encontram-se em fase de seleção e edição (cartas pessoais do XVIII; cartas oficiais da $2^{a}$. metade do XIX e do $\mathrm{XX})$.

\footnotetext{
14 Divisão proposta por Barbosa (1999 e 2005).
} 
Memórias e Diários de Viagem ${ }^{15}$ : esses tipos de texto revelam mudanças de tradição discursiva ao longo dos três séculos. Em cada época, observa-se um objetivo distinto. Embora as memórias tenham se tornado públicas através de sua impressão, até o final do século XIX, elas tinham em vista um leitor a quem a obra era oferecida. Os diários de viagem tinham por objetivo relatar os lugares por onde passavam os viajantes designados pela Côrte portuguesa, descrevendo a fauna, a flora, os povoados e todos os acontecimentos. Supõese que tanto as memórias, quanto os diários eram fruto de uma produção mais controlada e passível de revisões.

Cartas de leitores de jornais: aparecem no Brasil a partir do início do XIX; esse tipo de texto passa por modificações do XIX para o XX, em função da especialização das profissões (editores, revisores, jornalistas etc.), dentre outros fatores. São, em geral, cartas de reclamação dirigidas ao redator, cartas pessoais fictícias etc.. O tom emocional pode ser observado em todas estas cartas, o que afeta tanto a escolha do léxico, como as estratégias de argumentação.

Anúncios de jornais: da mesma forma que as cartas aos jornais, os anúncios passam por modificações do XIX ao XX, por exemplo, com o surgimento da profissão de publicitário e com os avanços tecnológicos (inclusão de imagens, cores, mapas etc.). Quanto à linguagem, os anúncios caracterizam-se por textos de composição heterogênea quanto à norma, mas é comum a todos um alto grau de nominalização das sentenças, típico do texto propagandístico. Eram geralmente ditados pelo anunciante ao tipógrafo do jornal, sem que passassem necessariamente por alterações ou revisões.

\section{Textos orais:}

NURC: são os inquéritos orais feitos no âmbito do Projeto de Norma Urbana Culta, na década de 70. Dividem-se em Diálogos entre 2 Informantes (D2), Diálogos entre Informante e Documentador (DID) e Elocuções Formais (EF).

Filoband e Português Popular em São Paulo: são inquéritos orais realizados por pesquisadores de dois projetos. O primeiro insere-se no Projeto Filologia Bandeirante, com o objetivo de resgatar arcaísmos em regiões rurais de SP, MG, GO etc. Selecionou-se aqui apenas os informantes paulistas. O segundo corpus são inquéritos realizados com informantes moradores de favelas paulistanas, muitos dos quais provêm de diversas regiões do nordeste brasilei-

15 Os dois gêneros foram considerados aqui juntos por formarem conjuntos de textos semelhantes e para que se pudesse fazer a comparação com os demais conjuntos de textos. 


\section{Verena Kewitz}

ro. Ambos têm como critério básico a baixa ou nenhuma escolaridade de seus informantes.

Embora os corpora não estejam distribuídos de forma equilibrada nos três séculos, como ressaltei na seção anterior, eles revelaram pistas interessantes a respeito da descrição espacial. Quanto maior a diversidade de gêneros textuais, mais precisa e rica poderá ser a análise, levando-se em conta sempre as particularidades e a história de cada texto. Em função disso, Simões \& Kewitz (2006b, 2009a,b,c) propuseram algumas categorias para melhor orientar as análises de fenômenos linguísticos:

Quadro 1. Categorias comunicativo-pragmáticas da escrita adaptadas de Henne \& Rehbock (1982) e Allwood (1976) apud Simões \& Kewitz

(2006b, 2009a,b,c)

\begin{tabular}{|c|c|}
\hline \multirow{3}{*}{ (i) Grau de publicidade } & particular \\
\hline & semi-particular \\
\hline & pública \\
\hline \multirow{3}{*}{$\begin{array}{l}\text { (ii) Grau de simetria entre os } \\
\text { escritores }\end{array}$} & ascendente \\
\hline & horizontal \\
\hline & descendente \\
\hline \multirow{3}{*}{ (iii) Fixidez temática } & sem fixidez \\
\hline & núcleo temático fixo \\
\hline & tema altamente fixo \\
\hline \multirow{3}{*}{$\begin{array}{l}\text { (iv) Grau de planejamento } \\
\text { do texto } \\
\text { (registro / níveis de fala) }\end{array}$} & livre (popular-comum) \\
\hline & semi-controlado (comum) \\
\hline & altamente controlado (formal) \\
\hline \multirow{9}{*}{$\begin{array}{l}\text { (v) Dimensões da ação } \\
\text { comunicativa }\end{array}$} & comandar, ordenar, forçar \\
\hline & acusar, repreender, recriminar \\
\hline & atacar, desafiar \\
\hline & requerer, pedir, implorar, solicitar \\
\hline & narrar, informar, relatar, reportar \\
\hline & $\begin{array}{l}\text { obedecer, confirmar, aceitar, concordar, } \\
\text { ceder }\end{array}$ \\
\hline & $\begin{array}{l}\text { protestar, refutar, negar, objetar, repudiar, } \\
\text { recusar, opor-se }\end{array}$ \\
\hline & aceitar, concordar, admitir, reconhecer \\
\hline & agradecer \\
\hline
\end{tabular}

Nesta pesquisa, assumo a hipótese de que a ativação das expressões espaciais de movimento está intimamente relacionada à tarefa comunicativa, 
ao núcleo temático, ao grau de planejamento de cada texto e ao grau de simetria entre os interlocutores.

Os resultados apresentados na tabela 1 da seção anterior permitem afirmar que os padrões de combinação MOVIMENTO + PERCURSO e MOVIMENTO + MODO perpassam todos os tipos de texto, embora com frequências distintas.

Cada gênero textual propicia o surgimento de expressões espaciais de movimento específicas, atrelado à tarefa comunicativa que fez gerar o texto. Os diários de viagem, por exemplo, apresentam grande quantidade de descrições estáticas e dinâmicas, uma vez que o autor, sobretudo no século XVIII, tinha a função oficial de relatar a um superior os fatos de sua viagem detalhadamente. Esse tipo de texto passa por renovações em sua tradição discursiva, como aponta Simões (2007: 202):

(...) a constituição dos gêneros textuais é fruto de adaptações e inovações de outros gêneros. (...) o avviso da tradição epistolar italiana dividiu-se em notícia e romance epistolar. Destes surgiram os diários de navegação ao final do século XV e a partir do XVI, dando conta aos monarcas dos novos descobrimentos. $\mathrm{Na}$ tradição portuguesa, das cartas notícia e dos diários, como é o caso da Carta de Pero Vaz de Caminha (1500) e do Diário de Viagem de Pero Lopes (1530), chegamos às notícias práticas, relatos escritos por bandeirantes e outros desbravadores, que registravam a progressão de suas viagens e seus feitos, numa mescla entre carta e diário. Paralelamente, à medida que se constituía uma nova identidade luso-brasileira, foi preciso registrar a diacronia dos fatos históricos que demarcavam eventos e feitos significativos da história do Brasil. Nesse momento surgem as memórias históricas, algumas ufanistas, (...) outras mais críticas (...).

As memórias encontradas na primeira metade do século XX, de certa forma, apresentam características semelhantes às do XIX. Mas esse gênero continuará a sofrer mudanças, até desaparecer completamente, do que diz respeito aos textos que o originaram. Mais adiante, o mesmo autor enfatiza:

(...) é bom lembrar que o gênero memória histórica passou por transformações (...). Em pleno século iluminista, elas cumpriam uma função política específi$\mathrm{ca}$, caracterizando-se como gênero intermediário entre a carta e a narrativa histórica. Os artigos de historiadores do século XX, principalmente da $2^{\mathrm{a}}$. metade do século, têm maior caráter de divulgação científica, e procuram apagar as marcas de envolvimento emocional que as memórias da $1^{\text {a }}$. metade do séc. XIX ainda traziam, ao narrar como os índios continuavam vivendo sogeitos as Aldeas, sofrendo inSolencias contrarias á liberdade doHomem. O que se quer dizer aqui, é que não é somente a grandeza gênero textual que define o uso e sim a suas especificidades inerentes, uma vez que os gêneros textuais podem ser portadores de diversas tradições discursivas. (op. cit., p. 294) 
As memórias da primeira metade do XX (Washington Luiz, 1918 e João Luís Promessa, 1930) selecionadas para a presente pesquisa, comprovam o que Simões aponta, tanto quanto o texto da segunda metade desse século.

A tabela 3 abaixo mostra os resultados em relação aos pontos do percurso presentes nos diários de viagem e memórias históricas em cada século ${ }^{16}$ :

Tabela 6: Distribuição dos pontos do percurso nas memórias por século

\begin{tabular}{|l|c|c|c|c|c|c|}
\hline & Inicial & Medial & Final & $\varnothing$ & combinações & total \\
\hline XVIII & 10 & 11 & 22 & 11 & 14 & $\mathbf{6 8}$ \\
\hline XIX & 3 & 7 & 6 & 0 & 10 & $\mathbf{2 6}$ \\
\hline XX & 2 & 4 & 5 & 0 & 13 & $\mathbf{2 4}$ \\
\hline total & 15 & 22 & 33 & 11 & 27 & 118 \\
\hline
\end{tabular}

Vê-se, pelo total para cada século, que há um declínio no número de ocorrências das expressões que descrevem os pontos do percurso do XVIII aos demais séculos. Isso comprova as afirmações de Simões (2007) a respeito da mudança de tradição discursiva desses gêneros.

As cartas dos três séculos, em geral, apresentam menos descrições espaciais, em parte devido à tarefa comunicativa e ao grau de simetria entre remetente e destinatário. Pelo total de dados apresentados na tabela 1, observa-se menor número de dados nas cartas que nas memórias dos séculos XVIII e XIX. Já nos dados do XX, vê-se certo equilíbrio entre os dois gêneros (27 para as memórias e 22 para as cartas). Isso não quer dizer necessariamente que houve mudança linguística, mas talvez apenas mudança nos textos.

O conjunto de cartas entitulado Aldeamentos de Índios (XVIII-XIX) merece algumas considerações, pelas narrativas que dão margem ao aparecimento de descrições espaciais de movimento ali presentes. Esse conjunto de cartas apresenta grau semiparticular de publicidade e normalmente revelam uma assimetria de grau ascendente entre remetente e destinatário. A fixidez temática em torno do cotidiano das aldeias é um dos aspectos que torna homogêneo o conjunto desses documentos. À uniformidade na produção e à assimetria entre interlocutores, alia-se a gama de tarefas comunicativas desempenhadas pelos religiosos por meio delas. Muitos destes documentos são relatos recriminatórios, ora pelo comportamento dos índios, ora pela precária situação

16 Esse resultados foram obtidos a partir da análise dos pontos do percurso em dados coletados em 1000 palavras, em média, por tipo de texto e por cada metade de século. 
em que se encontram as aldeias e de como são tratados pelos aldeados. Em consequência disso, além da crítica, dos protestos e do relato dos acontecimentos, as mesmas cartas trazem em seu bojo o pedido de intervenção das autoridades superiores. As dimensões da ação comunicativa mais frequentes nessas cartas são: acusar, recriminar; requerer, solicitar; narrar, relatar, informar; obedecer, confirmar, aceitar; protestar, negar, recusar, refutar. Dentre essas dimensões, é na tradição discursiva da narrativa que se observa a descrição do deslocamento no espaço físico. Vejamos um exemplo ${ }^{17}$ :

(50) Excellentissimo SenhorReprezenta aV ossa Excellencia oSeo humilde Subprior daAldeia de Nossa Senhora daEscada Frei Callisto deSanta Elena ogrande desturbio emque seacha adita aldeia motivado dos filhos do Tenente Coronel Sebastiaõ deSiqueira, Sendo aCauza, deter admoestado ao dito Tenente puseSse cobro nosSeos filhos eescravos por Serem estes perturbadores das Almas da dita aldeia, vindo aella de noute ededia; efazendo as In-dias hirem aSua fazenda, como mediceraõ duas, que as achey de noute fora hindo correr adita Aldeia com oCapitam della, mais outro Indio. Vendo pois osditos moSsos queixavame Eu destes desturbios, enaõ Menos apartava as Indias na doutrina sobre amesma materia, tendo hido odito Seo Pay para a Villa cómeSsaraõ aendusir aos Indios, eIndias para menaõ obedecerem; deSorte que nem quem mecozin=haSse quiseraõ tiveSse, enem hu' Indio que tinha vindo defora, eRecolhido ácozinha athê eSse momandaraõ indusir pello Cappitam, emepuseraõ deSomana sem ter quem medê nada, esperando por algu' paSageiro para medar alguã agoa elenha. [espaço] Com estas desatençoens', edescortesias estou aquy por naõ dar a minima molestia ao Tenente. Sendo que naõ sey deixaria alguâ couza dita aos Seos filhos porlheter ad=vertido, oque aSsima digo. [espaço] Nestes termos posto oque fas admirar atodos, tenho feito tençaó feichar aIgreja, emehir para omeo Convento; porem como obediente Subdito naõ oquero fazer Sem dar parte aVossa Excellencia. [espaço] As Minhas Culpas saõ oquerer fazer aminha obrigaçaó attendendo para oServiço de Deos, ede Sua Magestade, que Deosguarde No zello que tenho da aldeia, eCulto Divino, naó digo nada; porque tudo deixo ao exame de Vossa Excellencia. [espaço] Equal odo administrador, preguntese atodos, e ainda aos mesmos Indios. [espaço] Dia da Ascençaó de Chri[st]o [dilacerado] estando detarde na Igreja emcómendandome a Deos, que Sabe Deos quem

17 Aqui foram retiradas as notas constantes na edição semi-diplomática (Simões \& Kewitz 2006a); o alinhamento foi desfeito para simplificar a leitura e por economia de espaço. 
Seemcómenda, vy ao Padre Companheiro comvozes alteradas naporta da Caza, aoque acodindo pregunteilhe oque tinha ou oque hera Socedido ? DiSseme odito Padre, Padre Subprior, vamonos embora feichemos aporta pois aquy nosnaó querem; Etornandolhe apreguntar acauza? MediSse, agora mediSse hua India, que o Capitam da aldeia tinhá ordem do Senbor Joseph para vegiar as Indias, que entraSsem dentro desta Casa alevar alguâ couza, compena de Serem a Soutadas, / Sendo que athê agora, meo Senbor, Sempre foi uzo, ehê em[tod]as as Aldeias /. Acómodei ao Padre dizendo: tiveSse paciencia athê avisar aVossa Exce-lencia; eComo acolera do Padre ainda estava alterada, cómeSsou agritar contra o Cappitam e achamarlhe alguns' nomes, que hê odezafogo, que podemos ter, por nesta aldeia nem tronco, nem prizaó hav[er] eSer oque mais metem des obedecido semfazer cazo algum doque lhedezia acerca da Aldeia . Neste cómenos appareceo elle dito Capitam comdous paos delenha por $\mathrm{d}[\mathrm{es}]$ farce, ecom huá faca deponta boa na maõ pi $<\mathrm{o}>\mathrm{s}$ jun to doPadre oque vendo Eu griteilhe eoPadre entrou aSella [a]buscar hu' faconete sem ponta, como setem visto para Sedefender; eapegando tambem noPadre, naõ para que imaginaSse Eu offend[e] ria ao Indio como se colhe daboa Rezaõ, Senaó para que naó chegaSse o Indio aofendello; ainda contudo isto, Seavançou ahu pao dehu' paSageiro dizendo hera para Sedefender. [espaço] Vendo elle isto, eoque lhediSse havia dar Cont[a] aVossa Excelencia, pois já metinha entrado em caza com amesmafaca entre hu' gibaõ, tendo mandado apegar emhuá India para [ac]astig[a]r, efoi visto do Companheiro, Eeu pello vi[sto] achei Ser arma defez[a] vestido, eCom agineta na $[\mathrm{m}] \mathrm{aoo}, \mathrm{pReguntandolhe} \mathrm{oque} \mathrm{queria,} \mathrm{foise} \mathrm{sahindo;}$ Ecomo detudo isto contando ao Tenente Coronel para o C[a]stigar, fes taó pouco Cazo, que imaginando Eu inquiriSse o Cazo, oque lhefez fo[y]

[p. 2] Dizerme naó ser posivel; tendo experiencia delle ser taó dezatento que nesta Aldeia diante do vezitador da Companbia, eoSubprior da Aldeia de Sã̃ Joseph atirou a hu' homem, que por lhenaõ apegar fogo aespingarda, o naó matou; Eagora a[p]ar[s]eo com ella para Seconhecer averdade detudo. [espaço] ASsim que logo Sepos asalvo hindo queixarse aVossa Excellencia antes que Eu ofizeSse . [espaço] Esta, Meo Senhor excellentiSsimo Conde hê aSumma verdade; eSepode Vossa Excellencia informar doque digo, tendo em Sã̃ Paulo o Padre Domingos Machado, que entaõ hera Subprior e na occaziaõ oqueria o Padre Vezitador mandar castigar, epr[e]nder, naõ obstante naõ 
Ser Indio dosSeos, pello atrevimento que entaõ uzou. [espaço] Demim, edoque Relato Socedido naõ digo mande Vossa Excellencia Saber, porque ninguem vio, eSó Eu que me achara na occaziaõ com oPadre Mas entenda Vossa Excellencia hê amesma verdade. [espaço] Epara meo abono basta dizerem todos oque Saõ estes Indios, eeste principalmente. [espaço] Edaquy podemos fielmente crer, que tendo esta $\mathrm{Al}=$ deia hu' Cappellaõ por nome Salvador Correa, detal Sorte ocorreraõ, que vendo Deos asdezatençoens que lhefizeraõ detal Sorte os castigou, que cómeSsaraõ amorrer daly por diante Sem confiçaõ tantos, que Se acabou adita Aldeia: Eestes que aquy estao, Saõ vindo denovo. Isto dizem os moradores; [espaço] Eelles dizem agora, como diSse hu' morador ouvira dizer ahu', que naõ queriaõ aquy Religiosos. [espaço] Isto hê oque querem para viverem como Gentio. [espaço] Eu naõ espero Senaó aordem de Vossa Excellencia, aquem veneroComo peSsoa deSua Magestade, eCatholico, que alias já metinha posto acaminho ; Enaõ Sem pouca cauza, pois naõ Só doque aquy ex perimentamos, Senaó ainda Sem nosdarem decomer, enem quererem fazer nada; que SepaSsamos hê com bem median[i] a pellos vezinhos noLodarem por Respeito de MiSsa, eConfiçaó, eestarem $\underline{6}$ Legoas dasFreiguezias. [espaço] Naõ Semeofferece mais, que ficar as ordens de Vossa Excellencia, epor entanto pedir aDeos pRospere huá Saude perfeita para que chegue aver aSenhora Condesa com aquelles jubilos, que Vossa Excellencia dezeja. Deosguarde aVossa Excellencia etc. Aldeinha 12 de Maio de1736

DeVossaExcellenciaExcellentiSsimo

Senhor Conde dasGalveasHumilde

Subdito eServo muito obediente

Frei Callisto deSanta Elena

Esta carta é bastante representativa do que argumentei acima: além das fórmulas de início e fechamento, inerentes a esse tipo de carta e pela assimetria entre rementente e destinatário, vemos um longo trecho (destacado em negrito na carta) em que o frei narra em detalhes o episódio ocorrido na aldeia, até mesmo para justificar para seu superior sua decisão de fechar a aldeia. Contextos como esses dão margem ao surgimento de expressões espaciais de movimento das formas mais diversas e com maior riqueza de detalhes.

Resultados quantitativos como os apresentados neste trabalho devem ser analisados de forma parcial, uma vez que a mudança de um gênero ou tradição discursiva não implica que haja mudança linguística, como bem observa Jacob (2001: 154) a respeito da representatividade dos textos antigos: 
quando uma forma lingüistica simplesmente não aparece no corpus porque os textos não dão margem ao seu uso, seja pela sua orientação temática, seja pela variedade lingüística representada nesse texto ${ }^{18}$ não quer dizer que ela tenha desaparecido. Para comprovar essa afirmação, concluo com a tabela 7 abaixo ${ }^{19}$ :

Tabela 7: Distribuição dos dados de movimento por tipologia textual e século

\begin{tabular}{|c|c|c|c|c|c|}
\hline & & Memórias & Cartas & \multicolumn{2}{|c|}{ total geral } \\
\hline \multirow{2}{*}{ XVIII } & $1 .^{\mathrm{a}}$ metade & 74 & 31 & 105 & \multirow{2}{*}{$\begin{array}{r}226 / \\
62,25 \%\end{array}$} \\
\hline & 2. ${ }^{a}$ metade & 88 & 33 & 121 & \\
\hline & & & & & \\
\hline \multirow{2}{*}{ XIX } & 1. ${ }^{a}$ metade & 16 & 17 & 33 & \multirow{2}{*}{$\begin{array}{c}88 / \\
24,25 \%\end{array}$} \\
\hline & 2. ${ }^{a}$ metade & 41 & 14 & 55 & \\
\hline & & & & & \\
\hline \multirow{2}{*}{$\mathrm{XX}$} & 1. ${ }^{\mathrm{a}}$ metade & 10 & 9 & 19 & \multirow{2}{*}{$\begin{array}{c}49 / \\
13,5 \%\end{array}$} \\
\hline & 2. ${ }^{\mathrm{a}}$ metade & 17 & 13 & 30 & \\
\hline & total parcial & $246 / \mathbf{6 8 \%}$ & $117 / \mathbf{3 2} \%$ & \multicolumn{2}{|c|}{363} \\
\hline
\end{tabular}

O percentual presente no total geral demonstra acima de tudo, uma mudança de tradições discursivas, tanto nas memórias, quanto nas cartas, o que confirma a citação de Jacob (2001) acima. Uma vez que mudaram todas as categorias arroladas por Simões \& Kewitz (2006b) ao longo desses três séculos, não se pode afirmar que houve mudança linguística, mas sim mudança dos objetivos comunicativos dos gêneros, da simetria entre escritores etc.

\section{Considerações Finais}

Neste trabalho, procurei analisar as expressões espaciais de movimento em corpora do Português Paulista nos séculos XVIII a XX.

Vimos que o português apresenta diversos padrões de combinação de propriedades semânticas no verbo e nas preposições, ainda que o resultado

18 Minha tradução.

19 Os dados desta tabela são os mesmos daqueles quantificados na tabela 1, item 2 deste artigo. 
quantitativo tenha apontado para maior frequência do padrão MOVIMENTO + PERCURSO. Mas não levar em conta a ocorrência das demais combinações significaria negar a criatividade e a complexidade linguísticas da mente humana.

Do ponto de vista diacrônico, é preciso atentar para as propriedades discursivas dos textos, isto é, as categorias a eles inerentes quanto a sua produção, seu entorno sócio-histórico. Esse cuidado se faz necessário quando se lida com gêneros diversos em períodos distintos. A dificuldade em interpretar dados diacrônicos está atrelada à nossa interpretação e avalisção de leitores contemporâneos. Além disso, as expressões espaciais podem representar cenas distintas dependendo de onde e quando foram ativadas.

Essa pesquisa demonstra que mais perguntas poderão surgir a respeito da organização e representação espacial no português, até que se consiga chegar a conclusões mais precisas sobre as mudanças no Português Paulista.

\section{Bibliografia}

ALMEIDA, Francisco José de Lacerda e. 1944 [1780]. Diários de Viagem. Nota-prefácio de Sérgio Buarque de Holanda. Rio de Janeiro, Imprensa Nacional.

BARBOSA, Afrânio Gonçalves. 2005. Tratamento dos corpora de sincronias passadas da língua portuguesa no Brasil. Em Lopes, C.R.S. (org.) A Norma Brasileira em Construção. Fatos linguísticos em cartas pessoais do século XIX. Rio de Janeiro, UFRJ / Faperj.

1999. Para uma história do português colonial: aspectos linguísticos em cartas de comércio. Rio de Janeiro, Tese de Doutorado, Universidade Federal do Rio de Janeiro, inédita.

BARBOSA, Afranio \& LOPES, Célia. 2006 orgs. Críticas, queixumes e bajulações na Imprensa Brasileira do século XIX: cartas de leitores. Rio de Janeiro, UFRJ/Faperj.

BATORÉO, Hanna J. 2008. Cognitive and lexical characteristics of motion in liquid medium: $A Q U A$-motion verbs in typologically different languages. In Psychology of Language and Communication. Vol. 12, Nr.2. Disponível em http://versita.metapress.com/content/ 9ktt155655779372/fulltext.pdf. Acesso em 04.05.2009.

2006. Expressão do movimento em água (AQUA-motion) no português europeu: contribuição para tipologia lexical. In LinguíStica. Rio de Janeiro, v. 2, n. 2, 167-277.

1998. Language Typology and Semantic Primitive of Space: evidence from European Portuguese. In Vilela, M. \& Silva, F. (orgs.) Actas do $1 .^{\circ}$ Encontro Internacional de Linguística Cognitiva. Porto.

BLANK, Andreas. 1999. Why do new meanings occur? A cognitive typology of the motivations for lexical semantic change. In Blank, A. \& Koch, P. (eds.) Historical Semantics and Cognition. Cognitive Linguistics Research 13. Berlin, New York: Mouton de Gruyter.

CASTILHO, Ataliba T. de. 2010. Nova Gramática do Português Brasileiro. São Paulo, Ed. Contexto.

2007. Abordagem da língua como um sistema complexo: contribuições para uma nova Linguística Histórica. In A.T. de Castilho, M. A. C. Torres Morais, R.E.V. Lopes \& 


\section{Verena Kewitz}

S.M.L. Cyrino (Eds.). Descrição, História e Aquisição do Português Brasileiro. Campinas: Pontes / Fapesp, pp. 329-360.

2005. Diacronia dos adjuntos adverbiais preposicionados no português brasileiro. In Massini-Cagliari et al. (orgs.) Estudos de Linguística Histórica do Português. Araraquara: Laboratório Editorial FCL/Unesp, S.Paulo: Cultura Acadêmica Editora. Série Trilhas Linguísticas, no 7.

2004. Diacronia das preposições do eixo transversal no Português Brasileiro. Em: Lígia Negri et alii (Org. 2004). Sentido e Significação. Em torno da obra de Rodolfo Ilari. São Paulo: Contexto, pp. 11-47.

CASTILHO, Ataliba T. de et alii. 2002. Gramaticalização de algumas preposições no Português Brasileiro do século XIX. Ouro Preto, V Seminário do Projeto Para a História do Português Brasileiro.

CASTILHO, Ataliba T. de \& PRETI, Dino. 1987, orgs. A linguagem falada culta na cidade de São Paulo: materiais para seu estudo. Vol. II - Diálogos entre dois informantes. São Paulo: T. A. Queiroz/FAPESP.

CASTILHO, Ataliba T. de \& PRETI, Dino. 1986 orgs. A linguagem falada culta na cidade de São Paulo: materiais para seu estudo Vol. I - EF - Elocuções formais. São Paulo: T. A. Queiroz.

CASTILHO DA COSTA, Alessandra (em preparação) Tradições discursivas em cartas de leitores de A Provincia de S. Paulo e do Correio Paulistano (de 1854 a 1901). Texto apresentado no I Congresso Internacional de Linguística Histórica, homenagem a Rosa Virgínia Mattos e Silva, Salvador, julho de 2009.

CIFUENTES FÉREZ, Paula. 2008. Motion in English and Spanish: A Perspective from Cognitive Linguistics, Typology and Psycholinguistics. PhD. Dissertation, Murcia University. Disponível em http://www.tesisenred.net. Acesso em 25.07.2009.

DIRVEN, René \& PÜTZ, Martin. 1996. The Construal of Space in Language and Thought. Cognitive Linguistics Research 8. Berlin, New York, Mouton de Gruyter.

ÉRNICA, Maurício. 2004. Uma metrópole multicultural na terra paulista. Centro de Estudos e Pesquisas em Educação, Cultura e Ação Comunitária. Terra paulista: história, arte e costumes / coordenação de Maria Alice Setubal [et al.]. São Paulo: CENPEC: Imprensa Oficial.

EVANS, Vivian. \& TYLER, Andrea. 2004. Rethinking English 'Prepositions of Movement'. The Case of To and Through. In H. Cuyckens, W. de Mulder \& T. Mortelmans (Eds.), Belgium Journal of Linguistics, 18 Amsterdam: John Benjamins, 2004. Disponível em http:// www 9. georgetown.edu/faculty/tyleran/Rethinking $\% 20$ English $\% 20$ prepositions $\% 20$ of $\% 20$ movement.pdf - Acesso em 09.10.2008.

GARCÍA-MIGUEL, José M. 2006. Los complementos locativos. In Company Company (org.) Sintaxis histórica de la lengua española. Primeira parte: La frase verbal. Vol. 2. México, UNAM.

GUEDES, Marymárcia \& BERLINCK, Rosane (2000, orgs.) E os prę̧os eram commodos... Anúncios de jornais brasileiros, século XIX. São Paulo, Humanitas / FFLCH /USP. Série Diachronica, vol. 2.

IBARREXTE-ANTUÑANO, Blanca Iraide. 2008. Path salience in motion events. In Guo et al. (eds.) Crosslinguistic Approaches to the Study of Language. Research in the tradition of Dan Isaac Slobin. London and New York: Psychology Press, 403-414.

2004. Dicotomías frente a continuos en la lexicalización de los eventos del movimiento. Revista española de lingüistica 34.2, 481-510. 
ILARI, Rodolfo, CASTILHO, Ataliba T. de, ALMEIDA, Maria Lúcia Leitão, BASSO, Renato \& KLEPPA, Lou-Ann. 2008. A Preposição. In Neves, M.H.M. \& Ilari, R (Orgs.) Gramática do Português Culto Falado no Brasil. Vol. II. Campinas, Ed. da Unicamp.

JACOB, Daniel. 2001. ¿Representatividad lingüística o autonomía pragmática del texto antiguo? El ejemplo del pasado compuesto. In Jabob \& Kabatek (eds.) Lengua medievaly tradiciones discursivas en la Peninsula Ibérica. Descripción gramatical - pragmática bistórica - metodología. Frankfurt am Main: Vervuert; Madrid: Iberoamericana.

KEWITZ, Verena. 2010. Double Path: a typology of Brazilian Portuguese. In SILVA, Augusto Soares da et al. (2010 orgs.) Comunicação, Cognição e Media. Braga: Publicações da Faculdade de Filosofia Universidade Católica Portuguesa Vol. 2.

2009. A noção de deslocamento no Português Paulista: uma abordagem cognitiva. In Hora, Dermeval da (org.) Anais do VI Congresso Internacional da Abralin. João Pessoa. CD-ROM.

2007. Gramaticalização e semanticização das preposições a e para no Português Brasileiro (Séculos XIX e XX). São Paulo, FFLCH/USP, Tese de Doutoramento, inédita.

LUÍS, Washington. 1980 [1918]. Na capitania de S. Vicente (1918). São Paulo: Editora Itatiaia / Editora da Universidade de São Paulo.

MORAES, Rubens B. de. 1979. Lembrança de Mário de Andrade: 7 cartas. São Paulo, Digital Gráfica.

Notícia - $1^{a}$ Prática - Que a da ao P. Me de Diogo Soares o Alferes José Peixoto da Silva Braga, do que passou na Primeira Bandeira, que entrou ao descobrimento das Minas do Guayases até sair na Cidade do Belém do Grão-Pará - 1737. Coleção Notícias Práticas: I. Biblioteca Virtual / Laboratório de Pesquisa em História Social /IFCS /UFRJ. Biblio Virt-LIPHIS, 2001.

Notícia - 2 a Prática - Dada ao P. M. Diogo Soares sobre a abertura do novo caminho pelo Piloto José Inácio, que foi e acompanhou em todo ele ao mesmo Sargento-mor Francisco de Souza e Faria. - 1727. Coleção Notícias Práticas: III. Biblioteca Virtual / Laboratório de Pesquisa em História Social / IFCS / UFRJ. Biblio Virt-LIPHIS, 2002, http://paginas.terra.com.br/arte/liphis/ NoticiaPratica_Jose_Inacio.pdf, acesso em 09.12.2006.

PIRES, Angelina. 2007. "Como peixe na água!” Contribuição para a tipologia lexical dos verbos de movimento em água (Aqua-motion) do tipo FLUTUAR. Disponível em www.clul.ul.pt/artigos/pires_angelina.pdf - Acesso em 04.05.2009.

PONTES, Eunice. 1992. Tempo e espaşo na Lingua Portuguesa. Ed. Pontes, Campinas.

PRETI, Dino e URBANO, Hudinilson. Orgs. 1989. A Linguagem Falada Culta na Cidade de São Paulo. Materiais para seu estudo. São Paulo: TAQ/Fapesp, vol. III, Diálogos entre o Informante e o Documentador.

SALOMÃO, Margarida. 2006. Teorias da linguagem: a perspectiva sociocognitivista. Ms.

SAMPAIO, Wany, SINHA, Chris \& SILVA SINHA, Vera da Silva. 2009. Mixing and mapping: motion, path and manner in Amondawa. In: J. Guo, E., Lieven, N. Budwig, S. Ervin-Tripp, K. Nakamura, \& ${ }^{a}$. O $z \ddot{E} \bullet \cdot l^{\circ}{ }^{\circ}$ kan (eds.), Crosslinguistic Approaches to the Study of Language. Research in the Tradition of Dan Isaac Slobin. London and New York: Psychology Press, 649-667.

SILVEIRA, Cláudia Damião L. de A. 2009. Edição do manuscrito Reminiscencias de Santos, do século $X X$ : estudo comparativo das ocorrências dos pronomes demonstrativos desse corpus com ocorrências dos séculos XVII, XVIII e XIX. Tese de Doutorado, São Paulo, FFLCH/USP.

SILVEIRA, Cláudia Damião L. de A. \& KEWITZ, Verena. 1999. Reminiscencias de Santos. Edição de um manuscrito de João Promessa do século XX. Inédito, Ms. 


\section{Verena Kewitz}

SIMÕES, José da Silva 2007. Sintaticização, discursivização e semanticização das orações de gerúndio no português brasileiro. São Paulo, FFLCH/USP. Tese de doutoramento, inédita, 2 volumes.

SIMÕES, José da Silva \& KEWITZ, Verena. 2009a. Normas linguísticas, história social, contatos linguísticos e tradições discursivas: transformando encruzilhadas em novos caminhos para a constituição de corpora diacrônicos. In Castilho, A.T. de (org.) História do Português Paulista. Vol. I, Série Estudos. Campinas, Publicações/IEL, FAPESP.

2009b. A constituição de corpora diacrônicos do português brasileiro e seus traços linguístico-discursivos. In Gärtner, E. \& Schönberger, A. (Eds.) Estudos sobre o Português Brasileiro. Frankfurt am Main: Valentia.

2009c. Tradições Discursivas e organização de corpora. In Aguilera, V. (org.) Para a História do Português Brasileiro. Vol. VII: Vožes, Veredas, Voragens. Tomo II. Londrina, Eduel.

2006a. Cartas Paulistas dos séculos XVIII e XIX. São Paulo: Ed. Humanitas, publicação em CD-ROM.

2006b. Traços linguístico-discursivos em corpora do Português Brasileiro. Estudos Linguísticos XXXV. São Carlos, UFSCar. Disponível em www.gel.org.br.

SLOBIN, Dan. 2006. What makes manner of motion salient? In M. Hickmann \& S. Robert (Eds.), Space in languages: Linguistic systems and cognitive categories. Amsterdam/Philadelphia: John Benjamins, pp. 59-82.

2004. The many ways to search for a frog: Linguistic typology and the expression of motion events. In S. Strömqvist \& L. Verhoeven (Eds.), Relating events in narrative: Typological and contextual perspectives in Translation. Mahwah, NJ: Lawrence Erlbaum Associates, pp. 219257.

1996. Two Ways to Travel: Verbs of Motion in English and Spanish. In Thompson, S. \& Shibatani, M. (Eds.) Grammatical Constructions: Their Form and Meaning. Oxford: Clarendon Press.

STEFANOWITCH, Anatol \& ROHDE, Ada. 2004 The goal bias in the encoding of motion events. In Radden/ Panther (eds.) Studies in Linguistic Motivation. Cognitive Linguistics 28. Berlin/ New York, Mouton de Gruyter, p. 249-267.

TALMY, Leonard. 2005. Attention Phenomena. In Geeraerts, D. \& Cuyckens, H. (eds.) Handbook of Linguistics. Oxford University Press. Disponível em http://linguistics.buffalo.edu/ people/faculty/talmy/talmyweb/recent/attention.pdf - Acesso 15.03.2008.

2000a. Toward a Cognitive Semantics. Vol. I: Concept Structuring Systems. Cambridge, Massachusetts, MIT Press.

2000b. Toward a Cognitive Semantics. Vol. II: Typology and Process in Concepts Structuring. Cambridge, Massachusetts, MIT Press.

TAUNAY, Alfredo D’Escragnolle Taunay, Visconde de (s/d). A retirada da Laguna-episódio da Guerra do Paraguai. São Paulo: Ediouro. (Prestígio). Biblioteca Virtual do Estudante de Língua Portuguesa http://www.bibvirt.futuro.usp.br, acesso em 25.01.2007.

TEIXEIRA, José. 1998. Modelos cognitivos e orientação intrínseca dos objetos. In Vilela, M. \& Silva, F. (orgs.) Actas do $1 .^{\circ}$ Encontro Internacional de Linguistica Cognitiva. Porto.

WENZ, Karin. 1996. Iconicity in verbal descriptions of space. In Dirven, René/ Pütz, Martin (eds.)

The Construal of Space in Language and Thought. Cognitive Linguistics Research 8. Berlin, New York, Mouton de Gruyter. 
ZEQUINI, Anicleide. 2004. A fundação de São Paulo e os primeiros paulistas: indígenas, europeus e mamelucos. Centro de Estudos e Pesquisas em Educação, Cultura e Ação Comunitária. Terra paulista : história, arte e costumes / coordenação de Maria Alice Setubal [et al.]. São Paulo: CENPEC: Imprensa Oficial.

ZLATEV, Jordan \& YANGKLANG, Peerapat. 2004. A third way to travel: The place of Thai and serial verb languages in motion event typology. In S. Stromqvist \& L. Verhoeven (Eds.), Relating events in narrative: Typological and contextual perspectives. Mahwah, NJ: Lawrence Erlbaum Associates, pp.159-190.

Recebido em: 05/dez./2010

Aprovado em: 05/mai./2011 